\title{
The Relations between Cadmium, Zinc and Oxidative stress in Oligoasthenozoospermic Men
}

\author{
Marwa A. Ahmed ${ }^{1}$ and Dalia Abd El-Aziz ${ }^{2}$ \\ Physiology Department ${ }^{1}$ and Dermatology \& Andrology Department ${ }^{2}$, \\ Faculty of Medicine, Assiut University
}

\begin{abstract}
Background: Cadmium (Cd) has been found to accumulate in male reproductive organs and induce male reproductive toxicity in several animal species. Objective: To study the levels of Cadmium and Zinc in blood and seminal plasma of oligoathenozoospermic men and to investigate their possible role and their relation to oxidative stress in pathophysiology of oligoathenozoospermia. Study Design: Blood and seminal plasma were collected from thirty primary infertile males with oligoasthenozoospermic, and 30 control subjects. Cadmium (Cd), zinc ( $\mathrm{Zn})$, malondialdehyde (MDA) and superoxide dismutase (SOD) activity were estimated in all samples. Results: The serum and seminal concentrations of Cd and MDA of oligpasthenozoospermic group were significantly higher than those of control groups. Levels of blood and seminal plasma of $\mathrm{Zn}$ and SOD activity of infertile men were significantly lower than those of control group. The seminal plasma levels of Cd of oligoathenozoospermic group were correlated positively and significantly with MDA levels in seminal plasma. However, there were significant negative correlations between seminal plasma levels of $\mathrm{Cd}$ and seminal levels of $\mathrm{Zn}$ and seminal SOD activity ,sperm count and sperm motility. There were inverse correlations between seminal plasma levels of MDA and SOD activity, sperm count and sperm motility in oligoathenozoospermic group. The results also shows that there was a positive and significant correlation between the seminal SOD activity and sperm motility in infertile men. Seminal plasma levels of Zinc were negatively and significantly correlated with sperm motility of oligoathenozoospermic group. Conclusion: Cadmium may have adverse impacts on semen quality and male reproductive health. The pathophysiological mechanism of high Cadmium levels in oligoathenozoospermic men is probably through induction of oxidative stress. Lowered levels of zinc may contribute to infertility through its significant effects on semen motility. There is competitive mechanism of interaction between $\mathrm{Zn}$ in relation to $\mathrm{Cd}$ in oligoathenozoospermic men
\end{abstract}

\section{INTRODUCTION}

The general population is exposed to metals at low concentrations either voluntarily through supplementation or involuntarily through intake of contaminated food and water or contact with contaminated soil, dust, or air. Some metals, such as cadmium (Cd), lead, arsenic, and mercury, are nonessential xenobiotics that can be measured in most of the general 
population $^{(\mathbf{1})}$. Because widespread human exposure have been demonstrated, there is growing concern for adverse health effects associated with low-level exposures encountered in the environment. Human and animal evidence suggests that these metals may have adverse impacts on male reproductive health at relatively low levels. For example, Cadmium (Cd) has been linked to poor human semen quality and DNA damage $^{(2)} . \mathrm{Pb}$ and $\mathrm{Cd}$ are highly toxic metals for humans and other mammals. Both are pervasive in the human environment and accumulate in the human body over a lifetime, including prenatal life (especially $\mathrm{Pb})^{(3)}$.

Several trace elements have been shown to be essential for testicular development and spermatogenesis. Zinc $(\mathrm{Zn})$ in human semen seems to play an important role in the physiology of spermatozoa. $\mathrm{Zn}$ deficiency leads to gonadal dysfunction, decreases testicular weight, and causes shrinkage of seminiferous tubules ${ }^{(4)}$. It has been noted that $\mathrm{Zn}$ has a relationship with many enzymes in the body and can prevent cell damage through activation of the antioxidant system ${ }^{(5)}$. Zinc is an essential component of the oxidant defense system and functions at many levels ${ }^{(\mathbf{6})}$. One study has shown that $\mathrm{Zn}$ deficiency in the diet paves the way for cell damage in the rat testis ${ }^{(7)}$.

The imbalance between reactive oxygen spiecies (ROS) production and total antioxidant capacity (TAC) corresponding to oxidative stress is correlated with male infertility and the exposure of the spermatozooa to reactive oxygen speieces has been associated with cellular injury that includes DNA damage and lipid peroxidation $(\mathrm{LP})^{(\mathbf{8})}$. In fact, the excess of LP as represented by high levels of malondialdehyde (MDA) product may cause changes in the sperm characters, decreased fluidity and flexibility of the sperm membrane, and diminishing of the fertilization potential. This indicates that LP could be harmful to male sperm and reproductive system ${ }^{(9)}$.

\section{Aim of the work:}

To study the levels of Cadmium and Zinc in blood and seminal plasma of oligoathenozoospermic men and to investigate their possible role and their relation to oxidative stress in pathophysiology of oligoathenozoospermia.

\section{PATIENTS, MATERIALS \& METHODS}

\section{Patients:}

This study included 60 non smoker males aged 20 - 40 years. It was carried in Department of Dermatology and Andrology and Physiology Department, Faculty of Medicine, Assiut University from December 2007 until October 2008 The protocol was approved by the Faculty of Medicine, Assiut University ethical committee, and informed consent was obtained from each patient before the collection of samples. The participants were classified into: Group A: included 30 oligoasthenozoospermic male partners with sperm count less than 20 millions $/ \mathrm{ml}$, total motility $<50 \%$ ), Group B: included 30 normozoospermic healthy fertile control males selected from 
general population (whose partners had conceived within a year and have sperm count greater than 20 million $/ \mathrm{ml}$, total motility $>50 \%$.

\section{Selection Criteria:}

All patients had regular unprotected intercourse for at least 12 months without conception and had normal hormonal profile. Their partners were having normal and regular menstrual cycles without any uterine pathology or hormonal disturbance. A detailed background history and physical examination were taken from both husband and wife.

The exclusion criteria were as follows: 1- Factors in the individual's history that have a possible influence on male infertility, as suggested by the World Health Organization (WHO)(10) (eg, history of diabetes mellitus, long-term medication, urinary tract infection, sexually transmitted disease, or testicular injury), 2- Clinically detected abnormalities (small testicular volume or varicocele ). 3- Patients with previous groin/scrotal surgery or chronic alcohol intake were also excluded.

\section{Semen collection:}

Semen samples were obtained by masturbation into $50 \mathrm{ml}$ sterile polystyrene jars after an abstinence period of 3 to 5 days. After liquefaction, samples were processed by conventional analysis to determine the volume, sperm count, and sperm motility. Motility was assessed at room temperature according to $\mathrm{WHO}$ criteria $^{(10)}$

After semen analysis, spermatozooa were immediately separated from seminal plasma by centrifugation $(100 \mathrm{x} \mathrm{g}$ for $10 \mathrm{~min}$ at room temperature).Supernatants were collected and stored at $-70{ }^{\circ} \mathrm{C}$.

\section{Blood collection:}

Blood samples $(6 \mathrm{ml})$ were collected from controls and patients. The samples were taken from an anticubital vien and were transferred to chilled sterile disposable tubes. $3 \mathrm{ml}$ was heparinized and separated as plasma and the rest was separated as serum after centrifugation at 3,000 r.p.m. for $20 \mathrm{~min}$. Plasma and serum were stored immediately at $-20^{\circ} \mathrm{C}$ until assay.

\section{Methodology:}

Determination of Cadmium and Zinc:

Serum and seminal plasma cadmium $(\mathrm{Cd})$ and zinc $(\mathrm{Zn})$ levels were estimated by atomic absorption spectrometry Determinations of the concentrations of $\mathrm{Cd}$ were performed by graphite furnace atomic absorption spectrometry (Perkin-Elmer 5100 PC AAS, Zeeman furnace module, Furnace cooling System and Autosampler AS-70, Norwalk, USA) using pyrolytic transverse heated graphite atomizer tubes. Cadmium at $228.8 \mathrm{~nm}$ with hollow cathode lamps.

Determination of Malondialdehyde (MDA) and Superoxide dismutase (SOD) activity:

Levels of MDA in seminal plasma were assessed using thiobarbituric acid reactivity. The product of reaction between malondialdhyde and thiobarbituric acid was measured according to Ohkawa(11).Determination of SOD activity in the seminal plasma was done according to Misra and Fridovich (12).

Statistical Analysis: 
In the present study, the data were statistically analyzed using computer database (Prism program, Graph pad version 3.0). Data comparisons were performed by using two tailed unpaired student t-test and the correlations between the biochemical parameters were performed using (ANOVA) with a statistical significance of $\mathrm{P}<0.05$ was used (spearman's rank correlation coefficient). Levels of significance (P) were considered as following: (1) $\mathrm{P}>$ 0.05 , not significant; (2) $\mathrm{P}<0.05$, significant; (3) $\mathrm{P} \leq 0.01$, highly significant and the results are presented as mean \pm SD (13).

\section{RESULTS}

Data concerned with semen volume, sperm count and motility of both studied groups are presented in table (1).

In this study, it was found that there was a significant difference among the mean $\mathrm{Cd}$ levels in the examined groups, as the mean serum and seminal plasma $\mathrm{Cd}$ levels of control group were significantly lower than oligoathenozoospermic $(P<0.001)$. Generally, the mean serum levels of $\mathrm{Cd}$ were significantly higher than the mean seminal plasma levels in both examined groups $(P<0.001)$, Table (2).

It was found that serum and seminal plasma levels of $\mathrm{Zn}$ of control group were significantly higher than those of oligoathenozoospermic group $(\mathrm{p}<0.001)$. The MDA concentrations in plasma and seminal plasma of oligoasthenozoospermic group were significantly higher compared with control group $(P<0.001)$. The mean of plasma and seminal SOD activity were significantly higher in control group, compared with the oligoasthenozoospermic group $(P$ $<0.001$ ) (Table 2).

Table (3) shows that serum $\mathrm{Cd}$ levels have positive correlations with seminal Cd levels $(r=0.384, P<0.05)$ and plasma concentrations of MDA $(r$ $=0.74, P<0.001)$ and have negative correlations with plasma levels of SOD $(r=-0.624, P<0.001)$ and sperm motility $(\mathrm{r}=-0.424, \mathrm{P}<0.05)$.

The seminal plasma levels of $\mathrm{Cd}$ of oligoathenozoospermic group were correlated positively and significantly with MDA levels in seminal plasma ( $r$ $=0.964, P<0.001)$. However, there were negative significant correlations between seminal plasma levels of $\mathrm{Cd}$ and seminal levels of $\mathrm{Zn}(r=-0.873$, $P<0.001)$ and seminal SOD activity $(r=-0.827, \mathrm{P}<0.001)$, sperm count $(r$ $=-0.912, \quad P<0.001)$ and sperm motility $(r=-0.888, P<0.001)$. Table (3).

There were inverse correlations between seminal plasma levels of MDA and SOD activity $(r=-0.676$, $P<0.001)$, sperm count $(\mathrm{r}=-0.78$, $\mathrm{P}<0.001)$ sperm motility $(\mathrm{r}=-0.747$, $\mathrm{P}$ $<0.001)$ in oligoathenozoosperic group.

In all samples of infertile men, positive and significant correlation between the seminal SOD activity and sperm motility was established $(\mathrm{r}=$ 0.941, $\quad \mathrm{P}<0.001)$. Seminal plasma levels of Zinc were significantly and positively correlated with sperm motility of oligoathenozoospermic group $(\mathrm{r}=0.915, \mathrm{p}<0.001)$ Table (4).

Figure (1A) shows that there was inverse correlation between plasma levels of MDA and of SOD activity of 
oligoathenozoospermic group $(r=$ $0.605, \quad P<0.001)$. There was an inverse correlation between plasma levels of MDA and sperm motility of oligoathenozoospermic group $(r=$ $.0459, \quad P \quad<0.05)$ Figure (1B).
Furthermore, as shown in Figure (1C), plasma levels of SOD activity were positively correlated with sperm motility $(\mathrm{r}=0.555, \mathrm{P}<0.01)$ in oligoathenozoospermic group.

Table (1): Semen biophysical characteristics in both studied groups

\begin{tabular}{lll}
\hline Characteristic & Control group & Oligoathenozoospermic group \\
\hline Number & 30 & 30 \\
\hline Volume of ejaculate $(\mathrm{ml})$ & $3.83 \pm 0.021$ & $3.9 \pm 0.02$ \\
\hline Sperm count $\left(\mathrm{X} 10^{6} / \mathrm{ml}\right)$ & $94.92 \pm 1.03$ & $11.53 \pm 1.14$ \\
\hline Motility $(\%)$ & $93.27 \pm 0.51$ & $44.78 \pm 1.4$ \\
\hline
\end{tabular}

Data are presented as mean $\pm S E$

Table (2): Levels of different parameters in both studied groups

\begin{tabular}{|l|l|l|}
\hline Parameter & Control group & Oligoathenozoospermic group \\
\hline Serum Cd (ug/l) & $1.1 \pm 0.09$ & $1.42 \pm 0.014^{\mathrm{a}}$ \\
\hline Seminal plasma Cd (ug/l) & $0.86 \pm 0.01$ & $1.18 \pm 0.015^{\mathrm{a}}$ \\
\hline Serum Zn (ug/l) & $141.3 \pm 1.7^{\mathrm{b}}$ & $116.5 \pm 2.27$ \\
\hline Seminal plasma Zn(ug/l) & $271.7 \pm 4.1^{\mathrm{b}}$ & $192.9 \pm 4.54$ \\
\hline Seminal MDA(nmol/l) & $1.23 \pm 0.01$ & $3.36 \pm 0.02^{\mathrm{a}}$ \\
\hline Plasma MDA(nmol/l) & $14.2 \pm 0.08$ & $16 \pm 0.15^{\mathrm{a}}$ \\
\hline Seminal SOD activity(U/ml) & $22.08 \pm 0.22^{\mathrm{b}}$ & $13.47 \pm 0.12$ \\
\hline Plasma SOD activity(U/ml) & $137.6 \pm 1.53^{\mathrm{b}}$ & $79.5 \pm 0.68$ \\
\hline
\end{tabular}

Data are presented as mean \pm SE, Cd: Cadmium, Zn: Zinc, MDA :malondialdahyde, SOD: superoxide dismutase.

a: $P<0.001$ as compared to the control group , $b: P<0.001$ as compared to the oligoathenozoospermic group. 
Table (3): Multiple correlations analysis between Cd levels (in serum and SP) and Zn levels, MDA, SOD activity and the semen parameters in oligoathenozoospermic group.

\begin{tabular}{|c|c|c|c|c|}
\hline \multirow{2}{*}{ Parameters } & \multicolumn{2}{|l|}{ Serum Cd } & \multicolumn{2}{|l|}{ SP Cd } \\
\hline & Coefficient ( $r$ ) & $\mathbf{P}$ & Coefficient (r) & $\mathbf{P}$ \\
\hline Serum $\mathrm{Zn}$ & 0.007 & NS & -0.019 & $\mathrm{NS}$ \\
\hline SP Zn & 0.0141 & NS & -0.873 & $<0.001^{* * *}$ \\
\hline SP Cd & 0.384 & $<0.05^{*}$ & - & - \\
\hline SP MDA & 0.312 & NS & 0.964 & $<0.001^{* * *}$ \\
\hline Plasma MDA & 0.740 & $<0.001^{* * *}$ & 0.037 & NS \\
\hline SP SOD & -0.304 & NS & -0.827 & $<0.001^{* * *}$ \\
\hline Plasma SOD & -0.624 & $<0.001^{* * *}$ & -0.333 & NS \\
\hline Sperm count & -0.083 & NS & -0.912 & $<0.001^{* * *}$ \\
\hline Sperm motility & -0.424 & $<0.05^{*}$ & -0.888 & $<0.001^{* * *}$ \\
\hline
\end{tabular}

SP: Seminal plasma, Cd: Cadmium, Zn: Zinc, MDA: malondialdahyde, SOD: superoxide dismutase.

NS: non significant

Table (4): Multiple correlations analysis between semen parameters (sperm count and motility) and seminal plasma of MDA, SOD activity and Zinc in oligoathenoazoospermic group

\begin{tabular}{lllll}
\hline \multirow{2}{*}{ Parameters } & \multicolumn{2}{l}{ Sperm count } & \multicolumn{2}{c}{ Sperm motility } \\
\cline { 2 - 5 } & $\boldsymbol{r}$ & $\boldsymbol{P}$ & $\boldsymbol{r}$ & $\boldsymbol{P}$ \\
\hline MDA & -0.780 & $<0.001$ & -0.747 & $<0.001$ \\
SOD activity & 0.126 & $\mathrm{NS}$ & 0.941 & $<0.001$ \\
Zinc & 0.049 & $\mathrm{NS}$ & 0.915 & $<0.001$ \\
\hline \multicolumn{2}{l}{ MDA: malondialdahyde, SOD: superoxide dismutase, NS: non significant }
\end{tabular}

MDA: malondialdahyde , SOD: superoxide dismutase ,NS: non significant 
(A)
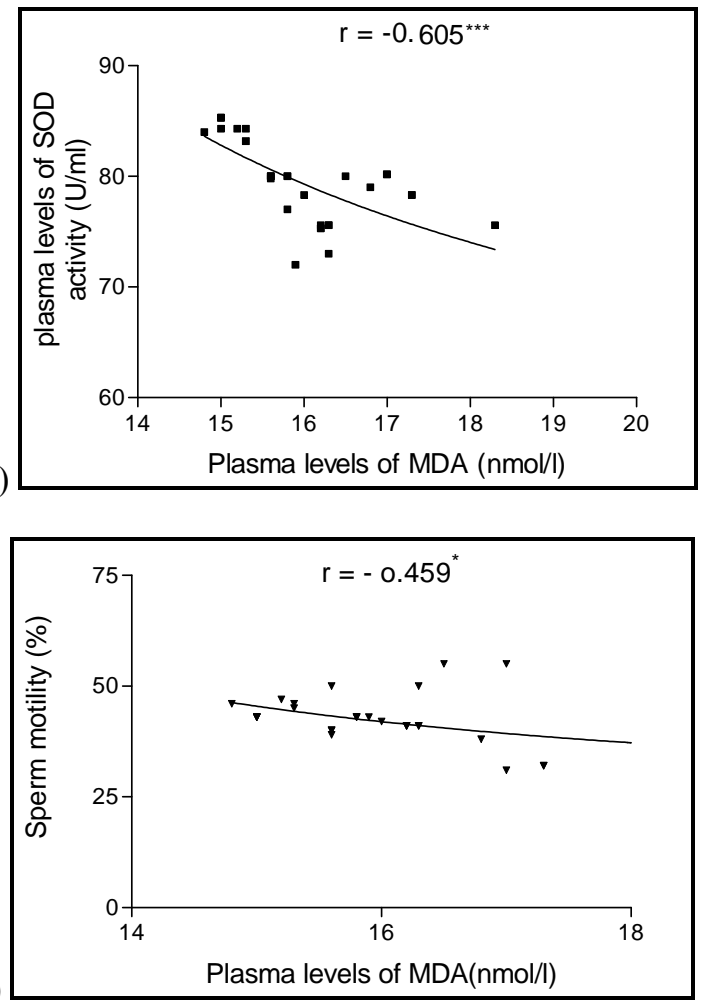

(B)

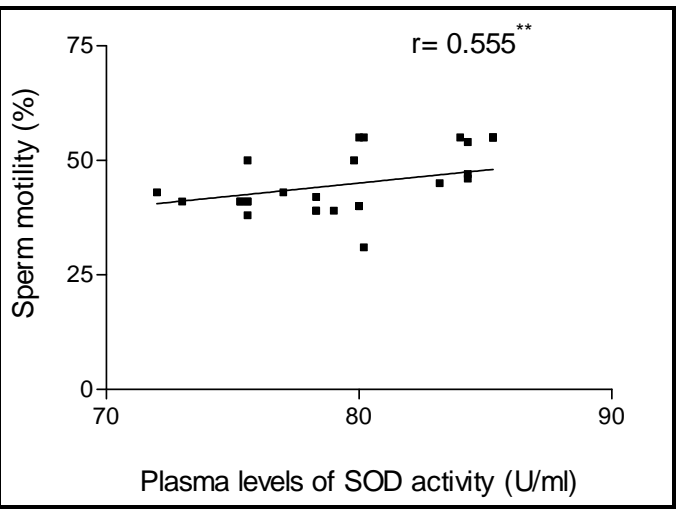

Figure (1): Multiple correlations analysis between plasma levels of MDA and SOD activity and Sperm count in oligoathenozoospermic (A) Inverse correlations between levels of MDA and SOD activity in plasma. (B): Inverse correlation between plasma levels of MDA and sperm count. (C): Positive correlation between plasma levels of SOD activity and sperm count . MDA: malondialdehyde, SOD: superoxide dismutase, $* * *=0.001, * *=0.01$ and $*=0.05$. 


\section{DISCUSSION}

It has long been established that agents such as cadmium, which are known reproductive toxicants, implicated in occupational hazards are found to accumulate in human semen ${ }^{(\mathbf{1 4})}$. However, the subjects in this study were recruited from occupationally unexposed population.

A high level of cadmium in serum of oilgoathenozoospermic patients were significantly higher than control subjects, this was explained by Omu et $\mathrm{al}^{(\mathbf{1 5})}$ who reported that a high level of cadmium was the possible cause of asthenozoospermia in smokers. Cigarette smoking is an important variable when considering the effect of both lead and cadmium exposure on human health. Cigarette smoke is a major source of airborne environmental lead and cadmium exposure. A single cigarette has been reported to contain $1.5 \mu \mathrm{g}$ of cadmium $^{(16)}$. Although smoking was excluded in the subjects investigated in our study, the incidence of unwilling exposure to second-hand cigarette smoke is very high in Eygpt. Unlike in the most developed countries, there are no smoking restrictions in public places in Egypt except hazardous areas such as petrochemical filling stations. Another explanation of high levels of $\mathrm{Cd}$ in infertile patients is that environmental discharge of cadmium due to the use of petroleum products, combination of fossil fuels (petroleum and coal) and municipal refuge contribute to airborne cadmium pollution and possibly introduce high concentrations of this potential reproductive toxicant into the environment ${ }^{(17)}$.
The seminal plasma levels of $\mathrm{Cd}$ in oligoathenozoospermic patients were significantly higher than control group indicating that there is systemic and cellular $\mathrm{Cd}$ toxicity in oligoathenozoospermic patients. Since the testes is known to serve as one of the important targets of $\mathrm{Cd}^{(\mathbf{1 8 )}}$, it is likely that cadmium elicits its toxic effect, probably expressed as infertility ${ }^{(19)}$.

Zinc, a critical element in male reproductive function, is normally secreted in enormous amounts by the prostate gland. Zinc and copper are bound to a small cysteine-rich metalbinding protein, metallothionein (MT), which has been identified in the male mammalian reproductive organs such as testis,epididymis, prostate and seminal vesicles In general, MT is important in the homeostasis of essential metals, like zinc and copper, and provides protection from toxic metals such as cadmium ${ }^{(20)}$.

In this study, there were significant low serum and seminal plasma zinc levels in oligathenozoospermic patients than the control group. This was explained by Amara et al. ${ }^{(\mathbf{1 8})}$ who reported that there is competitive mechanism of interaction of $\mathrm{Zn}$ in relation to $\mathrm{Cd}$ toxicity.

The lowered levels of zinc of oligoathenzoospermic men may also be explained by that $\mathrm{Cd}$ appears to mainly affect the distribution of $\mathrm{Zn}$ in the body. Because $\mathrm{Zn}$ is required for optimum activity of $>200$ enzymes including those involved in the synthesis and repair of DNA and RNA, and thus related protein synthesis and tissue repair response, this may have multiple adverse 
consequences. However, alterations in the amount and/or biologic availability of $\mathrm{Zn}$ in certain body compartments (e.g., through Cdrelated decrease in the capacity of MT to provide optimum supply of $\mathrm{Zn}$ to the cell) may influence sperm proliferation, maturation, and viability $^{(21)}$. Moreover, dietary $\mathrm{Cd}$ probably produced testicular lesions indirectly by decreasing testicular $\mathrm{Zn}$; this decrease seems to be due to sequestration of $\mathrm{Zn}$ by $\mathrm{Cd}$-induced hepatic and renal metallothioneins ${ }^{(22)}$.

Seminal plasma levels of zinc were positively correlated with sperm motility and this positive correlation may be explained by that Zinc in seminal plasma stabilizes the cell membrane and nuclear chromatin of spermatozoa. It may play a regulatory role in the process of capacitation and acrosome reaction $^{(23)}$.

Normally, a balance is maintained between the amount of ROS produced and antioxidants. Cellular damage arises when this equilibrium is disturbed, especially when the cellular scavenging systems cannot eliminate the increase in ROS. The scavenging potential in gonads and seminal fluid is normally maintained by adequate levels of SOD, catalase, and probably glutathione peroxidase and reductase which are mainly produced by the male accessory sex glands ${ }^{(24)}$.

In this study the oxidative stress (OS) status was evaluated in infertile men by assessing the levels of LP product (MDA) in semen. MDA concentrations in plasma and seminal plasma of oligoasthenozoospermic group were significantly greater compared with control group. In contrast, the mean of plasma and seminal SOD activity was significantly lower in oligoasthenozoospermic group compared with the control group. This was explained by that $\mathrm{Cd}$ is highly toxic metal in humans and other mammals. This heavy metal can induce OS through its capacity to interact with ROS, increasing its oxidant activity or by affecting membrane integrity ${ }^{(25)}$.

The seminal plasma levels of $\mathrm{Cd}$ of oligoathenozoospermic group were correlated positively and significantly with MDA levels in seminal plasma .However, there were significant negative correlation between seminal plasma levels of $\mathrm{Cd}$ and seminal SOD activity ,sperm count and sperm motility, The explaination is that spermatozoa are particularly susceptible to OS-induced damage, because their plasma membranes contain high concentration of polyunsaturated fatty acids (PUFA) and their cytoplasm contains low concentrations of scavenging enzymes $^{(\mathbf{2 6})}$. Lipid hydroperoxides are stable under physiological conditions until they contact transition metals such as cadmium or copper salts. These metals or their complexes cause lipid hydroperoxides to generate alkoxyl and peroxyl radicals, which then continue the chain reaction within the membrane and propagate the damage throughout the cell. Propagation of LPO depends on the antioxidant strategies employed by spermatozoa. One of the by-products of lipid peroxide decomposition is malondialdehyde ${ }^{(27)}$.

This explanation was supported by Amara et al. ${ }^{(18)}$ who reported that there was concomitant increase in 
generation of free radicals, such as $\mathrm{H}_{2} \mathrm{O}_{2}$ and $\mathrm{OH}$, in the testes of the Cdtreated rats and the interaction between $\mathrm{Cd}$ and essential trace elements could be one of the reasons for decreased antioxidant enzymes in the rat testis.

Both levels of seminal plasma of $\mathrm{Cd}$ and MDA in the present study have significant negative correlations with sperm count and motility, these results were inaccordance with Fatma et al. ${ }^{\text {(26) }}$ who reported that MDA concentration in semen of all patients was also positively correlated with acrosome abnormality and cytoplasmic retention and the high levels of OS were correlated with impairment of the acrosome reaction owing to protein cross-linking and LP.

These results can be explained by that $\mathrm{H}_{2} \mathrm{O}_{2}$ diffuses across the membranes into the cells and inhibits the activity of some vital enzymes such as glucose-6-phosphate dehydrogenase (G6PD) via the hexose monophosphate shunt controls the intracellular availability of NADPH, which is then used as a source of electrons by spermatozoa to fuel the generation of ROS by an enzyme system known as NADPH oxidase.

Another hypothesis involves a series of interrelated events resulting in a decrease in axonemal protein phosphorylation and sperm immobilization, both of which are associated with a reduction in membrane fluidity that is necessary for sperm-oocyte fusion ${ }^{(28)}$. On the other hand, the low seminal $\mathrm{O} 2$ scavenging capacity could support an inadequate seminal defense against free radical toxicity, which, in turn, could affect sperm motility ${ }^{(\mathbf{1 8})}$.

\section{Conclusion:}

Cadmium may have adverse impacts on semen quality and male reproductive health. The pathophysiological mechanism of high Cadmium levels in oligoathenozoospermic men is probably through induction of oxidative stress. The evaluation of oxidative status might have an indicative value on the diagnosis of male infertility.

Lowered levels of zinc may contribute to infertility through its significant effects on semen motility. There is competitive mechanism of interaction between $\mathrm{Zn}$ in relation to $\mathrm{Cd}$ in oligoathenozoospermic men.

\section{REFERENCES}

1. Centers for Disease Control and Prevention (CDC). (2005): Third National Report on Human Exposure to Environmental Chemicals. Washington, DC

2. Xu DX, Shen HM, Zhu QX, Chua $L$, Wang QN and Chia SE. (2003): The associations among semen quality, oxidative DNA damage in human spermatozoa and concentrations of cadmium, lead and selenium in seminal plasma. Mutat Res 534:155-163.

3. Newton D, Pickford CJ, Chamberlain AC, Sherlock JC, Hislop JS. (1992): Elevation of lead in human blood from its controlled ingestion in beer. Hum Exp Toxicol ;11:3-9 .

4. Bedwal RS and Bahuguna $A$. (1994): Zinc, copper and selenium in 
reproduction.Experientia.; 50 : 626-640.

5. 5- Ozturk A, Baltaci AK, Mogulkoc R, Oztekin E, Sivrikaya A, Kurtogh $\mathrm{E}$ and Kul A (2003): Effects of zinc deficiency and supplementation on malondialdehyde and glutathione levels in blood and tissue of rats performing swimming exercice. Biol Trace Elem Res ; 94: 157-166.

6. Sato $M$ and Bremner I. (1993): Oxygen free radicals and metalothionein. Free Radical Biol Med; 14: 325-327.

7. Oteiza PI, Adonaylo VN, Keen CL (1999): Cadmium-induced testes oxidative damage inrats can be influenced by dietary zinc intake. Toxicology ;10: 137: 1322.

8. De Lamirande $E$ and Gagnon C. (1995): Impact of reactive oxygen species on spermatozoa: A balancing act between beneficial and detrimental effects. Hum Reprod; 10:12-15.

9. Aitken RJ, Clarskon JS and Fishel S. (1989): Generation of reactive oxygen, lipid peroxidation and human sperm function. Biol Reprod ;41:183197.

10. World Health Organization. WHO (1999): Laboratory Manual for the Examination of Human Semen and SpermCervical Mucus Interactions. New York: Cambridge University Press.

11. Ohkawa H, Ohishi $\mathbf{N}$ and Yagi K (1979): Assay for lipid peroxides in animal tissues by thiobarbituric acid
reaction.Anal.Biochem ; 95: 351358.

12. Misra HP and Fridovich (1976): The role of superoxide anion in the autoxidation of epinephrine and a simple assay for superoxide anion. J.Biol.Chem.; 247 (10):31703175.

13. Knapp GR and Miller MC (1992): Tests of statistical significance: Regression and Correlation. In: Clinical Epidemiology and Biostatistics $1^{\text {st }}$ Eddition. Williams and Wilkins, Baltimore, Maryland; PP: 255 274.

14. Gagnon C (1988): The role of environmental toxins in unexplained male infertility. Seminars in Reproductive Endocrinology; 6: 369-376.

15. Omu AE, Dashtu H, Mohammed AT and Mattappallil AB (1995): Significance of trace elements in seminal plasma of infertile men. Nutrition 11 suppl 5: 502-505.

16. Chia SE, $X u$ B, Ong CN, Tsakok FM and Lee ST (1994): Effect of cadmium and cigarette smoking on human semen quality. International Journal of Fertility and Menopausal Studies; 39 292-298

17. De Rosa M, Zarrilli S, Paesano L, Carbone U, Boggia B, Petretta M, Masto A, Cimmino F, Puca G, Colao A, and Lombardi $G$ (2003): Traffic pollutants affect infertility in men. Human Reproduction; 18: 1055-1061.

18. Amara $S$, Abdelmelek $H$, Garrel C,Guiraud P, Douki Th, 
Luc Ravanat J,favier A, Sakly $M$ and Ben Rhouma K (2008): Preventive Effect of Zinc Against Cadmium-induced Oxidative Stress in the Rat Testis. Journal of Reproduction and Development, Vol. 54, No. 2:129-134.

19. Akinloye O, Arowojolu AO, Shittu OB and Anetor JI (2006): Cadmium toxicity: a possible cause of male infertility in Nigeria. Reproductive Biology;6 (1): 17 -30.

20. Omu $A E$ and Fernandes $S$ (2001): The Relationship between Zinc/Cadmium Ratio in Human Semen: Effect on Immune Response.The Kuwait Medical Journal, 33 (1): 38-43.

21. Telisman S, Cvitkovic $P$, Jurasovic J, Pizent A,Gavella $M$ and Rocic B (2000): Semen Quality and Reproductive Endocrine Function in Relation to Biomarkers of Lead, Cadmium, Zinc, and Copper in Men. Environmental Health Perspectives ;108: 45 -53.

22. Souza V, Escobar Mdel C, Bucio L, Hernandez $E$ and Gutierrez-Ruiz MC (2004): Zinc pretreatment prevents hepatic stellate cells from cadmium-produced oxidative damage. Cell Biol Toxicol; 20: 241-251.

23. Ali H, Ahmed M, Baig M, Ali M (2007): Relationship of zinc concentrations in blood and seminal plasma with various semen parameters in infertile subjects. Pak J Med Sci .; 23 : 111-114.

24. Jeulin C, Soufir JC, Weber P, Laval MD and Calvayarac $R$ (1989): Catalase activity in human spermatozoa and seminal plasma. Gamete Res; 24: 185196.

25. Oteiza $P$ I, Mackenzie $\mathbf{G} \mathbf{G}$ and Verstraeten S (2004): Metals in eurodegeneration: involvement of oxidants and oxidant-sensitive transcription factors", Mol. Aspects Med. ;25: 103-115.

26. Fatma BA, Dammak I, Attia $H$, Hentati B, and Keskes LA. (2009): Lipid Peroxidation and Antioxidant Enzyme Activities in Infertile Men: Correlation With Semen Parameter. Journal of Clinical Laboratory Analysis 23: 99-104.

27. Saleh RA and Agrawal A. (2002): Oxidative Stress and Male Infertility: From Research Bench to Clinical Practice. Journal of Andrology (23):737 752.

28. Agarwal A, Makker $K$ and Sharma R. (2008): Clinical Relevance of Oxidative Stress in Male Factor Infertility: An Update. American Journal of Reproductive Immunology; 59: 2-11. 


\section{العلا قة بين الكادميوم والزنك و التوتر الناتج عن الأكسدة في الرجال ذوي قلة وضعف حركة الحيو انات المنوية}

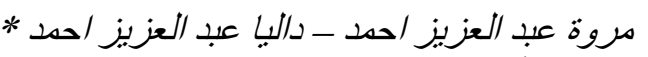

قسم الفسيولوجيا- قسم الأمر اض الجلديةو التناسلية* ـ كلية الطب ـ ـ جامعة أسيوط

يعد الكادميوم و الزنك من العناصـر الأثريـة التي تؤ ثر علي الجهاز التناسلـي لدي الذكور

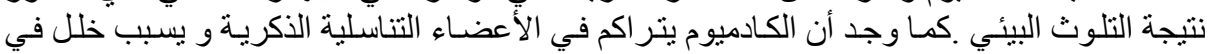
الوظائف التناسلية الذكرية.

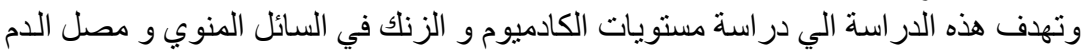

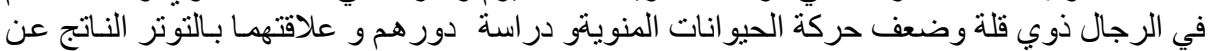

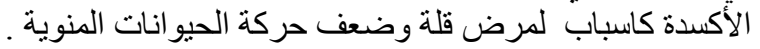

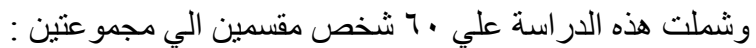

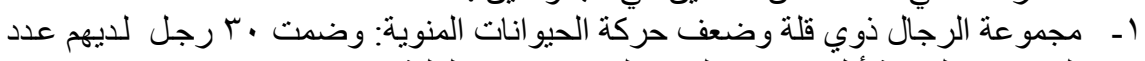

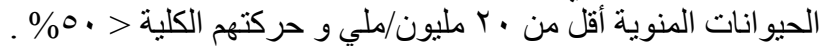

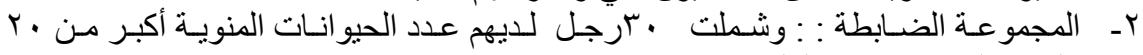

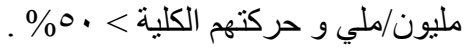

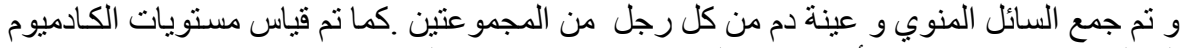

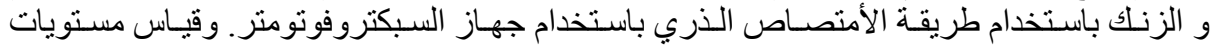

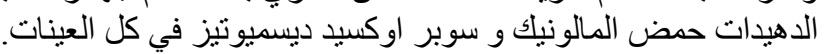

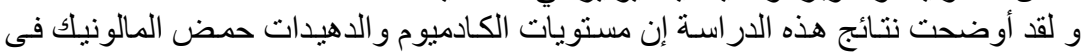

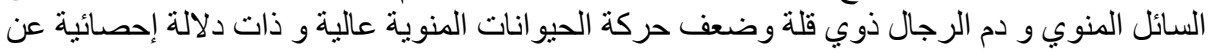

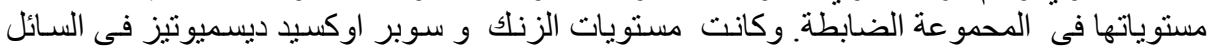

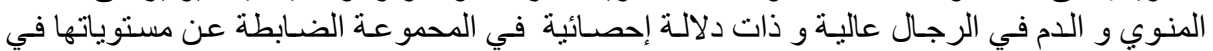

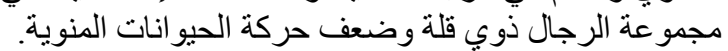

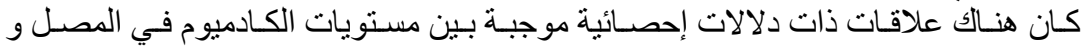

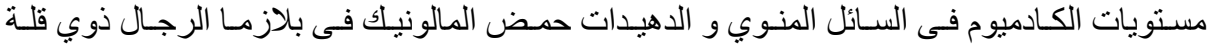

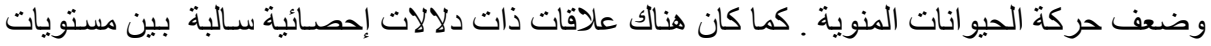

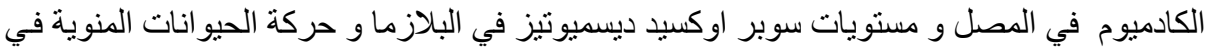

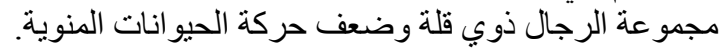

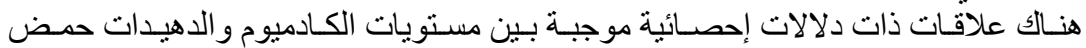

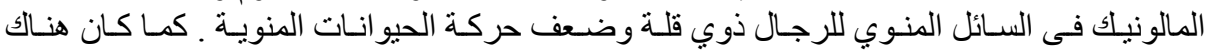

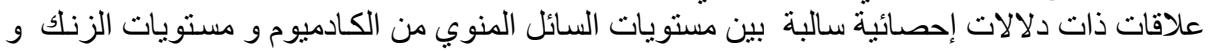

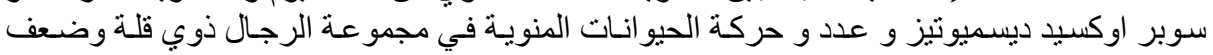

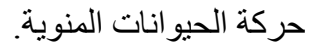

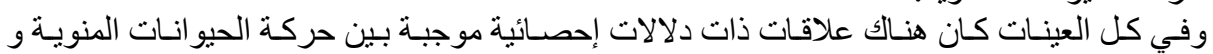

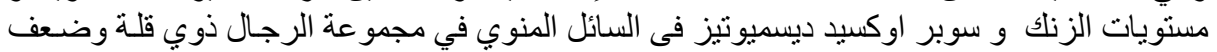
حركة الحيو انات المنوية.

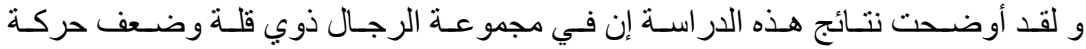

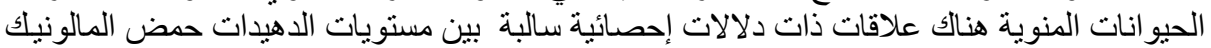




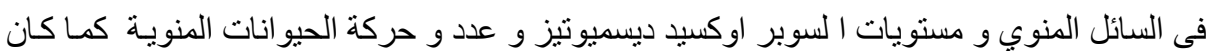

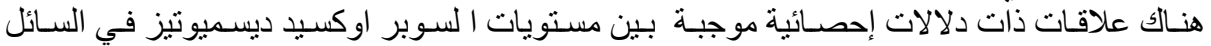

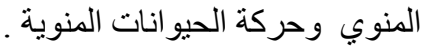

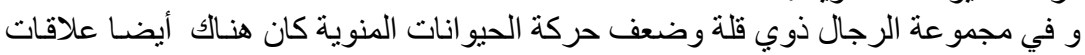

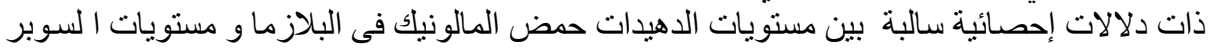

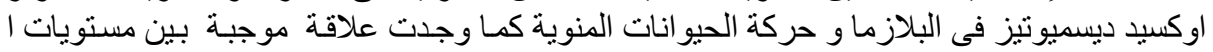

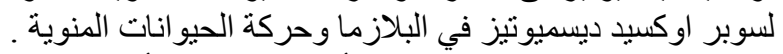

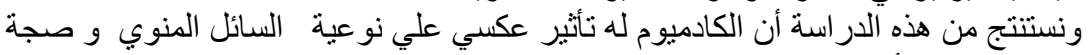

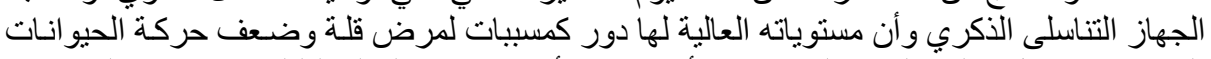

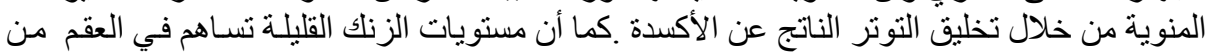

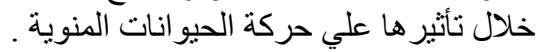

